Article

\title{
China's Rare Earths Production Forecasting and Sustainable Development Policy Implications
}

\author{
Xibo Wang ${ }^{1}$, Mingtao Yao ${ }^{2}$, Jiashuo $\mathrm{Li}^{3, *}$, Kexue Zhang ${ }^{4,5}$, He Zhu ${ }^{6,7}$ and Minsi Zheng ${ }^{8}$ \\ 1 Institute of Software Chinese Academy of Sciences, Beijing 100190, China; xibo@iscas.ac.cn \\ 2 Energy Research Institute, National Development and Reform Commission, Beijing 10038, China; \\ yaomt@eri.org.cn \\ 3 Department of New Energy Science and Engineering, School of Energy and Power Engineering, \\ Huazhong University of Science and Technology, Wuhan 430074, China \\ 4 Intelligent Control Technology Branch of China Coal Research Institute, Beijing 100013, China; \\ zhkexue@163.com \\ 5 State Key Laboratory for Geomechanics and Deep Underground Engineering, \\ China University of Mining and Technology (Beijing), Beijing 100083, China \\ 6 Institute of Geographic Sciences and Natural Resources Research, Chinese Academy of Sciences, \\ Beijing 100101, China; zhuh.14b@igsnrr.ac.cn \\ 7 University of Chinese Academy of Sciences, Beijing 100049, China \\ 8 Institute of Economics, Tsinghua University, Beijing 100084, China; zhengminsi@163.com \\ * Correspondence: lijiashuo@hust.edu.cn; Tel.: +86-27-8755-8598
}

Academic Editor: Vincenzo Torretta

Received: 19 March 2017; Accepted: 5 June 2017; Published: 10 June 2017

\begin{abstract}
Because of their unique physical and chemical properties, Rare earth elements (REEs) perform important functions in our everyday lives, with use in a range of products. Recently, the study of China's rare earth elements production has become a hot topic of worldwide interest, because of its dominant position in global rare earth elements supply, and an increasing demand for rare earth elements due to the constant use of rare earth elements in high-tech manufacturing industries. At the same time, as an exhaustible resource, the sustainable development of rare earth elements has received extensive attention. However, most of the study results are based on a qualitative analysis of rare earth elements distribution and production capacity, with few studies using quantitative modeling. To achieve reliable results with more factors being taken into consideration, this paper applies the generic multivariant system dynamics model to forecast China's rare earth elements production trend and Hubbert peak, using Vensim software based on the Hubbert model. The results show that the peak of China's rare earth elements production will appear by 2040, and that production will slowly decline afterwards. Based on the results, the paper proposes some policy recommendations for the sustainable development of China's—and the world's-rare earth elements market and rare earth-related industries.
\end{abstract}

Keywords: rare earths; sustainable development; production forecast; system dynamics model; policy recommendations

\section{Introduction}

The rare earth elements (REEs) are indispensable elements in modern industry, and are widely used in the new energy, new materials, energy conservation, environmental protection, aerospace, and electronic information industries. Because of their unique physical and chemical properties, REEs also perform important functions in our everyday lives, with use in a range of products [1]. Currently, there are 110 million tons of REEs reserves globally, half of which are located in China, 17.3 percent in Russia, and 11.8 percent in the United States. Besides those, sizeable deposits are also found in Brazil, 
India, Australia, Canada, and Greenland [2]. During the 1990s, China's REE production increased rapidly [3]. China has become the world's dominant producer, user, and exporter of REEs in recent decades, and accounts for about $90 \%$ of global REEs production [4]. Especially since 2004, the change of the world's REEs production has been synchronized with China's REEs production, since China's REEs production has considerably been close to the global REEs production.

As the world's largest REEs producer and supplier, previous studies have been focused on predicting the peak of China's REEs production and supply trends [2,5-7]. However, few studies in the field are done with quantitative methods. Most of the studies estimate the possible new REEs production capacity based on an understanding of REEs mines or projects worldwide.

Just as with other exhaustible resources, REEs will reach a production peak in theory no matter how much the production techniques advance. There are a number of commonly used forecasting techniques - such as logistic models and the Hubbert model — used to predict the peak production of exhaustible resources [8-11]. Among these models, the Hubbert model has been widely used in the study of exhaustible resources, since it successfully predicted, in 1956, that US oil production would peak in the 1970s, which provides us an important reference for our research. This paper attempts to build a system dynamics model using a generic Vensim to simulate China's REEs Hubbert peak and production trends based on a Hubbert model, and propose some policy recommendations for different countries based on our forecasting results.

\section{Literature Review}

\subsection{Research on China's REEs Supply}

Rare earth elements are a very important strategic resource in China, and the difficulty of obtaining rare earth-related data in China has always been a point of contention in the field of research. Therefore, there is not much literature on rare earth elements production prediction, but what literature there is can be divided into two categories. The first is forecasting the future supply of REEs based on the production capacity of the world's major REEs mines. Because it is an estimation made on the basis of the production capacity of REEs mines, the estimated results in the literature are relatively short-term. The second is forecasting medium- and long-term REEs production in China using a quantitative forecasting model.

In terms of forecasting future REEs production based on the capacity of REEs mines, some scholars analyze the world's REEs supply situation based on an analysis of the foreign REEs companies' production capacity and operation planning, REEs research programs in these companies, and Japan's overseas REEs investment projects [9-13]. Castor [14] thinks that REEs production in China may be influenced by export policies, domestic demand, and price, after analyzing the REEs export policies in China. Wübbeke [2] predicts REEs production and export volume in China, and points out that REEs policies in China may result in the reset of overseas REEs projects, based on an analysis of China's Rare Earth Development Plan and media reports. The reset of overseas REEs projects will weaken China's dominant position in REEs supply in the long term $[15,16]$. However, the above research on REEs production forecasts mainly focuses on estimating global and Chinese REEs production based on the current and premonitory production capacity of REEs mines or programs worldwide. The results are usually estimations of the production of the near future, rather than longer term.

In terms of forecasting medium- and long-term REEs production in China using a quantitative forecasting model, Wang et al. [17] predicted the production of the three major rare earth elements in China (namely, mixed rare earth, bastnasite, and ion-absorbed rare earth) before 2050 based on a generalized Weng model. They mentioned that the models chosen to forecast the production should fit the possibility of data acquisition. Unfortunately, there has been no information of mixed rare earths, ionic rare earths, and bastnaesite reserves released up to date. In this context, Wang et al. [17] chose a generalized Weng model which does not need reserves data to ensure the normal processing of research on the predictions of different kinds of rare earth elements. Moreover, a generalized Weng 
model just makes fitting predictions on the basis of previous production data, without taking factors including resource reserves and technological improvement into consideration.

\subsection{Prediction Model of Exhaustible Resource Production}

It is clear that the extraction of a definite resource must research a maximum point. In other words, its production will decline after this point [18]. The production characteristics of nonrenewable mineral resources makes it possible to predict by a number of commonly used forecasting techniques. The models adopted by many scholars are a Hubbert model, which is a typical bell curve mode first proposed by Hubbert [19-24], a modified logistic model [25,26], or some other type of bell curve model-such as a Gaussian model [22], Gompertz model [27], HCZ model [27,28], or generalized Weng model [29-33] to forecast nonrenewable mineral resource production. Among them, the Hubbert model and the generalized Weng model are the most influential, as they have been widely used in the field of exhaustible resource peak production prediction. The variables involved in the generalized Weng model are prediction model constants $a, b$, and c, and exploitation time $t$, among which the former three can be gotten from actual production by fitting. The variables involved in the Hubbert model are recoverable reserves and the undetermined coefficients $a$ and $b$, among which recoverable reserves can be gotten by querying, and the coefficients can be gotten from the actual observed value. By the comparison of the parameters in the two models, it is not difficult to find out that the Hubbert model takes recoverable reserves as its constrained variable, while the generalized Weng model does not. Thus, the Hubbert model is chosen as the predictive model in this paper. Moreover, system dynamics is a popular method used in forecasting production or the demand of mineral resources [34,35]. Frausto-solis et al. used a method called SAM-oil, which combines a simulated annealing metaheuristic with evolutionary computing techniques, statistical analysis, and a quality assessment of solutions to forecast oil production time series [36].

\subsection{Application of the Hubbert Model}

Hubbert [37] first studied the worldwide production trends of fossil fuels. Later, Hubbert [38] introduced the logistic curve, and simulated the production peak using historical data. The Hubbert model has been widely used in the prediction of exhaustible resource production since 1956, when it succeeded in forecasting the United States' oil peak production.

Many researchers have studied world and regional oil production peaks based on the Hubbert model and Hubbert's previous research [5-8,26,39-45]. Besides oil production peaks, the Hubbert model has also been widely used to forecast the production of other exhaustible resources. Many researchers use the Hubbert model to forecast world and regional coal production peaks, due to coal's non-renewability [19-24,46,47]. For natural gas, scholars have used the Hubbert model to predict its production and production peaks in China and throughout the world, and have obtained reasonable results [48-51].

\section{Methodology}

In view of the wide application of the Hubbert model, this paper attempts to build a system dynamics model using a generic Vensim to simulate China's REEs Hubbert peak and production trends based on the Hubbert model. Some policy recommendations for different countries are proposed, based on our forecasting results.

\subsection{Hubbert Model}

M.K. Hubbert first introduced the following logistic equation to estimate oil production [34,38], which is the so-called Hubbert model of this paper.

$$
\mathrm{Q}=\frac{\mathrm{N}_{\mathrm{R}}}{1+\mathrm{e}^{-\left(\mathrm{a} \times\left(\mathrm{t}-\mathrm{t}_{\mathrm{m}}\right)\right)}}
$$




$$
\begin{gathered}
\mathrm{P}=\frac{\mathrm{a} \times \mathrm{N}_{\mathrm{R}} \times \mathrm{e}^{\mathrm{a}\left(\mathrm{t}-\mathrm{t}_{\mathrm{m}}\right)}}{1+\mathrm{e}^{\left(\mathrm{a} \times\left(\mathrm{t}-\mathrm{t}_{\mathrm{m}}\right)\right)^{2}}} \\
\mathrm{e}^{-\left(\mathrm{a} \times\left(\mathrm{t}-\mathrm{t}_{\mathrm{m}}\right)\right)}=\frac{\left(\mathrm{N}_{\mathrm{R}}-\mathrm{Q}\right)}{\mathrm{a}}
\end{gathered}
$$

Using the above formula, the following result can be obtained:

$$
\begin{gathered}
\mathrm{P}=\mathrm{aQ}-\frac{\mathrm{aQ}^{2}}{\mathrm{~N}_{\mathrm{R}}}=\mathrm{aQ}\left(1-\frac{\mathrm{Q}}{\mathrm{N}_{\mathrm{R}}}\right) \\
\frac{\mathrm{P}}{\mathrm{Q}}=\mathrm{a}\left(1-\frac{\mathrm{Q}}{\mathrm{N}_{\mathrm{R}}}\right)=\left(\mathrm{a}-\frac{\mathrm{aQ}}{\mathrm{N}_{\mathrm{R}}}\right)=\mathrm{a}-\mathrm{mQ}
\end{gathered}
$$

where $\mathrm{P}$ refers to production; $\mathrm{Q}$ to cumulative production; NR to recoverable reserves; and $t_{\mathrm{m}}$ to the time of peak production. $m$ denotes the decay rate of production, which equals $a / N_{R}$, and is the parameter we set for easy calculating. "a" is the prediction parameter in the Hubbert model, and we call it the intrinsic growth rate. According to Formula (2), with other conditions being unchanged, "P (production)" becomes bigger when a gets bigger. The prediction parameter " $\mathrm{a}$ " has a decisive impact on the width of the Hubbert curve: when the prediction parameter " $a$ " is small, the curve is short and wide, and the peak of the curve shows late; when the prediction parameter "a" is big, the curve is tall and thin, and the peak of the curve shows early. According to formula (2), "a" should be calculated before "P". Let $\mathrm{m}=\mathrm{a} / \mathrm{UR}$ in formula (5). Then, formula (5) can be described as a line with the ordinate being the ratio of rare earth elements production and cumulative production $(\mathrm{P} / \mathrm{Q})$; the abscissa being rare earth elements cumulative production $(\mathrm{Q})$; the intercept being a; and the slope being $\mathrm{m}$. "a" and " $\mathrm{m}$ " can be calculated using regression methods.

However, Tao and Li [35] mentioned that using statistical regression for accurately estimating the parameters ' $\mathrm{a}$ ' and ' $\mathrm{m}$ ' remains questionable, and the correct fitted methodology remains to be found. The economist Michael Lynch [52] argues that the theory behind the Hubbert curve is too simplistic, and relies on historical data overly. Moreover, the Hubbert model does not consider likely resource growth, the application of new technology, basic commercial factors, or the impact of geopolitics on production [53]. In fact, the Hubbert model is a linear model that only shows a one-way causal relationship between variables. However, the variables in the model are mutually affected, which could be fully revealed by a system dynamic model. Moreover, a system dynamic model could describe and manage the dynamic evolution and the intrinsic stochastic behavior of a mass of factors inside the variables. This enables systematic dynamics models to simulate and calculate several variables at the same time, which is conducive to the finding of lagging relations between variables. Thus, systematic dynamics models based on the Hubbert model can show their advantage as a dynamic simulation model, and predict several variables at the same time. In addition, the parameter pilot function of the simulation software Vensim can simulate the change of resource growth, and the technical improvement in different scenes by parameter settings. Thus, considering the inherent flaws in the modeling, a system dynamics model is presented in this paper.

In the rest of the paper, we construct a system dynamics model to simulate the Hubbert peak using the Vensim software. Using the system dynamics model implemented in Vensim for the complex calculations has several advantages. First, the parameters can be calculated with more suitable values automatically. Second, a number of other relevant parameters (variables of production, actual production, cumulative production, reserves $(\mathrm{R})$ vs. production $(\mathrm{P})$, and annual proved reserves addition) can be calculated simultaneously if needed. Third, system dynamics modeling allows us to simulate different policy strategies in order to understand system feedback effects [54].

\subsection{Vensim Modeling}

The generic diagram is designed for the Hubbert peak model by the Vensim software. There are three types of variables, including two level variables (cumulative production and cumulative 
proven reserves), four rate variables (actual production, Hubbert production, proven reserves, and annual proven reserves addition), and six auxiliary variables (production, ' $a$ ', recoverable reserves, replacement rate, R vs. P, and delta reserves) (Figure 1). As long as we get the available statistical data for the three variables annual production $(\mathrm{P})$, reserves to production ratio $(\mathrm{R} / \mathrm{P})$, and recoverable reserves $\left(\mathrm{N}_{\mathrm{R}}\right)$, we may reliably predict the time when the Hubbert peak will appear and generate a production curve.

The first step of modeling the Hubbert peak is to input the statistical or simulating data into the diagram.

The second step is to build the relationship between the variables, writing the inflow equations that are presented in the Appendix A.

The core variable of this diagram is Hubbert production. The future Hubbert production is simulated with the standard Hubbert curve equation. All of the Hubbert production data describes the Hubbert production curve and Hubbert peak.

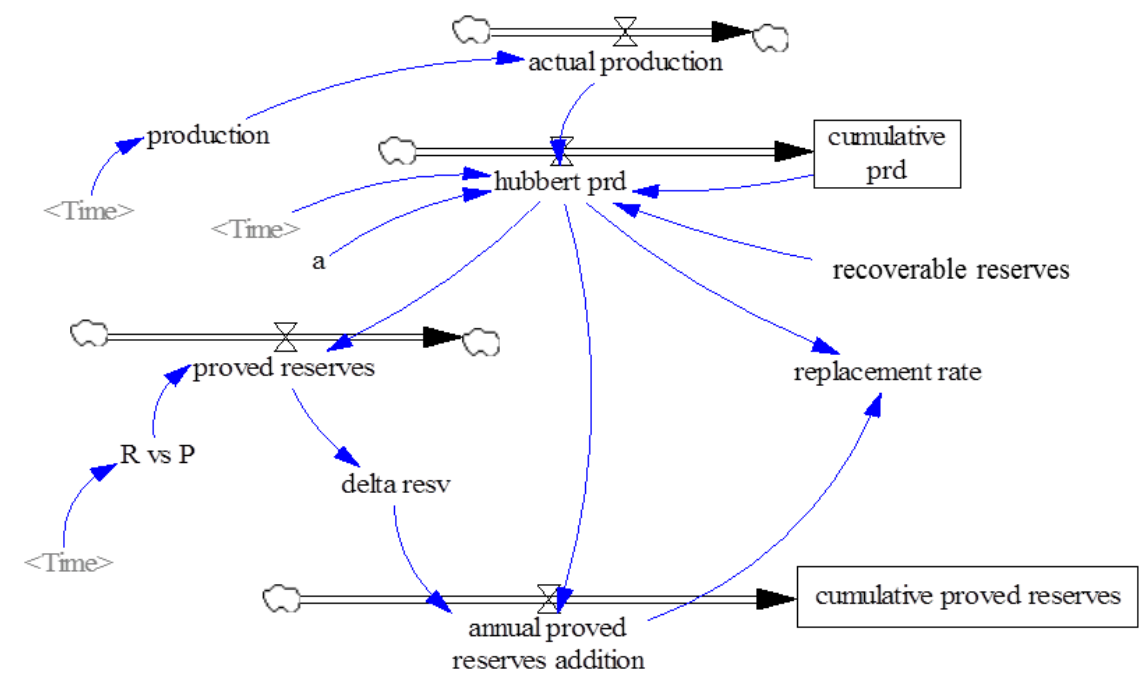

Figure 1. A generic Vensim diagram. Note: $\mathrm{R}$ vs $\mathrm{P}$ is reserves to production ratio; resv is reserves; prd is production.

\subsection{Data Description}

The historical data of China's REEs production from 1988 through 1993 are from The National Development and Reform Commission, Industry Coordination Department [55], and the data from 1994 through 2012 are from the USGS (U.S. Geological Survey) Mineral Commodity Summaries [56]. To obtain more accurate forecasting results, we simulated different scenarios based on different recoverable reserves and growth rates.

In addition, the initial values of the level variables need to be set, including cumulative production and cumulative proved reserves. Since the first simulating year is 2007 , the initial value of cumulative production is set to 1,232,830 tons, which equals the sum of all the production from 1988 to 2007 . The initial value of cumulative proved reserves is set to $89,000,000$ tons, which is the reserve base from the USGS [56].

\section{Results and Discussion}

Various possible future scenarios will appear. Therefore, predictions should have a 'possibility space'. In our case, a change in ' $\mathrm{N}$ ' or ' $\mathrm{a}$ ' will produce different forecasting results for peak time, production, as well as for the production trends. Consequently, we first make different scenarios for several recoverable reserves, each with the same intrinsic growth rate $\mathrm{a}=0.057$. Then, the sensitivity of the coefficient ' $a$ ' at constant $N_{R}$ is tested. 


\subsection{Scenario Analysis Based on Different Recoverable Reserve Values}

The different statistical standards result in different recoverable reserves statistics. We believe that there are two main reasons for the statistic disparity of reserves data: (i) the technological disparity in survey and different statistic caliber between China and the U.S. (the current technology in the US may survey more rare earth elements reserves); and (ii) the different interest in demand for rare earth elements between China and the U.S. Rare earth elements demand countries tend to announce that there are many more rare earth elements reserves in China than in other countries in order to make the situation of supply exceed demand, so that buyers can have the right of pricing rare earth elements. China tends to export rare earth elements at a higher price to cover the environmental cost of the rare earth elements' exploitation and separation, so it may release reserves data of the rare earth elements' exhaustion. We analyzed different scenarios for several recoverable reserves with the same intrinsic growth rate $\mathrm{a}=0.057$, which equals the average growth rate of China's REEs production between 1988 and 2011 [57].

(1) Scenario 1: $N_{R}=18,590,000$ tons. This recoverable reserve value is estimated by Su Bo, the Vice Minister of China's Ministry of Industry, who announced that the $\mathrm{N}_{\mathrm{R}}$ of China's REEs was $18,590,000$ tons on 20 June 2012. In this scenario, the peak for China's REEs production appears in 2038 , with a value of 264,900 tons. To facilitate the later comparison of the simulation scenarios, the results of Scenario 1 will be considered as the main results, and the equations are presented in the Appendix A.

(2) Scenario 2: $\mathrm{N}_{\mathrm{R}}=27,000,000$ tons. The USGS (U.S. Geological Survey) Mineral Commodity Summaries [56] estimated China's REEs reserves at 27,000,000 tons in 2009, which is used for the $\mathrm{N}_{\mathrm{R}}$ of this scenario. The results indicated that the peak for China's REEs production appears in 2045 , with a value of 384,700 tons.

(3) Scenario 3: $\mathrm{N}_{\mathrm{R}}=22,770,000$ tons. This estimate comes from the Situation and Policies of China's Rare Earth Industry, edited by the State Council of PRC, which announced that China's REEs reserves account for approximately 23 percent of the world's total. According to the USGS, the total world's REEs reserves are approximately $99,000,000$ tons [56]. Therefore, the $\mathrm{N}_{\mathrm{R}}$ value is approximately 22,770,000 tons. This scenario indicated that the peak for China's REEs production appears in 2042, with a value of 324,500 tons.

Based on the predicted results under these three scenarios above, China's REEs production will continue to display an upward trend for the next 30 years or so, and when production reaches the Hubbert peak in the middle of the 21st century, production will decline. The results are shown in Table 1 and Figure 2.

Table 1. The simulations results of three scenarios.

\begin{tabular}{cccc}
\hline & Scenario 1 & Scenario 2 & Scenario 3 \\
\hline Peak time & 2038 & 2045 & 2042 \\
Max production (tons) & 264,900 & 384,700 & 324,500 \\
\hline
\end{tabular}




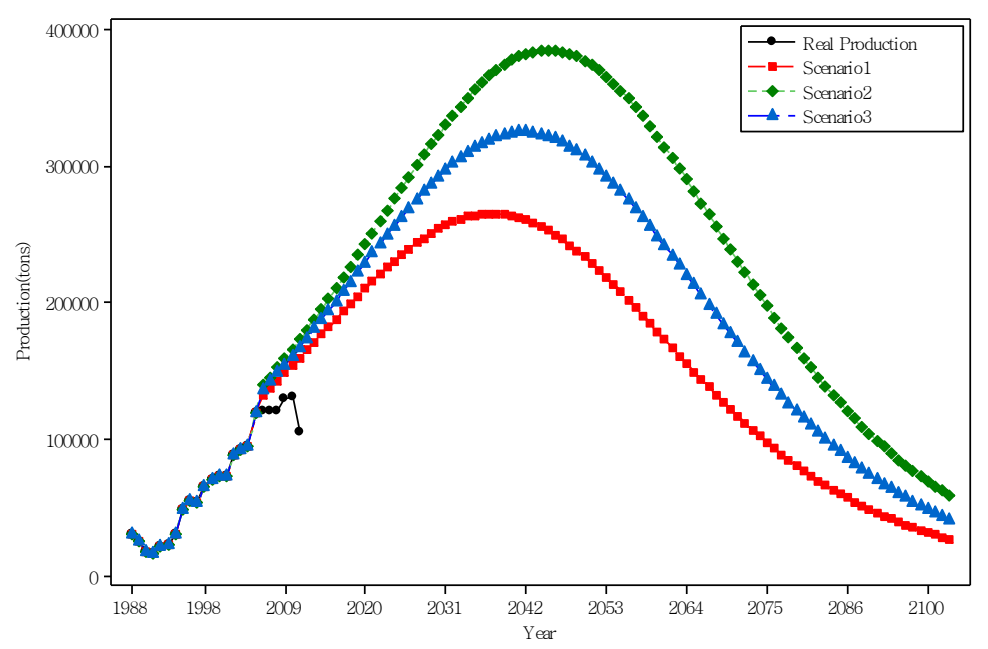

Figure 2. Three scenarios of China's REEs Hubbert peak.

\subsection{Scenario Analysis Based on Different a Values}

It is undeniable that technological advances, the development of REEs end-use industries, policy interventions, politics, and other factors will affect China's REEs production and peak time trends. Moreover, the intrinsic growth rate will be changed as all of the factors change together. Thus, we needed to test the sensitivity of the coefficient ' $a$ ' at a constant $N_{R}=18,590,000$ tons. The results are shown in Table 2 and Figure 3.

When a $=0.05$, the peak occurs in 2042 with a peak production of 232,400 tons. When a $=0.057$, the peak happens in 2038 with a peak production of 264,900 tons. Additionally, when a $=0.065$, the peak appears in 2034 with a peak production of 302,100 tons.

Table 2. Sensitivity analysis for intrinsic growth rate a ( $N_{R}=18,590,000$ tons).

\begin{tabular}{cccc}
\hline & $\mathbf{a}=\mathbf{0 . 0 5}$ & $\mathbf{a}=\mathbf{0 . 0 5 7}$ & $\mathbf{a}=\mathbf{0 . 0 6 5}$ \\
\hline Peak time & 2042 & 2038 & 2034 \\
Max production (tons) & 232,400 & 264,900 & 302,100 \\
\hline
\end{tabular}

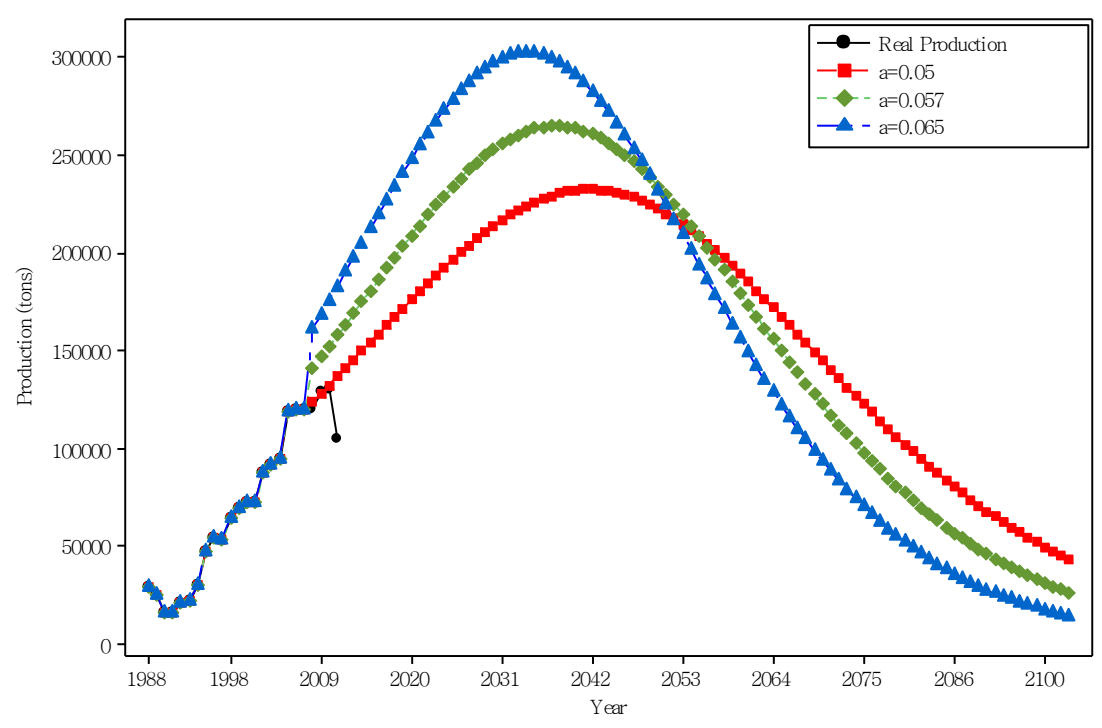

Figure 3. Sensitivity analysis for intrinsic growth rate 'a'. 


\subsection{Discussion}

This paper uses Hubbert model theory and Vensim to predict China's REEs production by constructing a system dynamics model. Compared with the traditional calculating methods for the Hubbert model, using the system dynamics model-including Vensim-to process the complex calculations has several advantages. First, the Hubbert model is a linear model that only shows a one-way causal relationship between variables. However, variables in the model are mutually affected, which could be fully revealed by a system dynamic model. Moreover, a system dynamic model could describe and manage the dynamic evolution and the intrinsic stochastic behavior of a mass of factors inside the variables. Therefore, the system dynamic method could yield "more suitable" values. Second, a number of other relevant parameters can be calculated simultaneously if needed. Third, policy tests can be conducted. Thus, this method is better than the traditional regression calculating methods for the Hubbert model.

According to the scenario simulations with different $N_{R}$ values, in Scenario 1 the Hubbert production of China's REEs will peak in 2038, with a production peak of 264,900 tons. In Scenario 2, the Hubbert production will peak in 2045, with 384,700 tons. In Scenario 3, the Hubbert production will peak in 2042, with 324,500 tons. The production of China's REEs will increase to 180,800 tons, 199,900 tons, and 191,900 tons by 2020 in the three scenarios, respectively. Therefore, the annual predicted data and the actual data are coincident exactly from 2005 to 2011 in Scenario 1, and the average difference is less than $10 \%$. In addition, the predicted results are quite close to the estimates of China's REEs production in 2020 shown in previous scholars' studies $[2,10,11,13,17]$ (Table 3).

Table 3. Comparison of production prediction results for China's REEs with the previous scholars' studies.

\begin{tabular}{ccccccccc}
\hline Year & \multicolumn{4}{c}{ Previous Scholars' Studies (tons) } & \multicolumn{3}{c}{ This Study (tons) } \\
\hline \multirow{2}{*}{2020} & Chen & Wübbeke & Hurst & Kingsnorth & Wang & sce1 & sce2 & sce3 \\
& $>170,000$ & $130,000-150,000$ & 160,000 & $225,000(2015)$ & 138,027 & 180,800 & 199,900 & 191,900 \\
\hline
\end{tabular}

Here, the sensitivity of the coefficient ' $a$ ' is tested with a constant $N_{R}=18,590,000$ tons. The results indicate that when $\mathrm{a}=0.05$, China's REEs production will peak in 2042, with a production of 232,400 tons; when $\mathrm{a}=0.057$, the peak will appear in 2038, with a production of 264,900 tons; and when $\mathrm{a}=0.065$, the peak will occur in 2034, with a production of 302,100 tons.

By comparison, it indicates that the time of peak and production are significantly dependent on the ' $\mathrm{N}_{\mathrm{R}}$ ' and ' $\mathrm{a}$ ' values. In other words, the key to accurate theoretical predictions is to determine reasonable values of ' $\mathrm{N}_{\mathrm{R}}$ ' and ' $\mathrm{a}$ '. In fact, advances in technology tend to raise $\mathrm{N}_{\mathrm{R}}$, which promotes production, and delays the timing of the peak. From the scenarios' predicted results, when ' $N_{R}$ ' is large, China's REEs production life cycle will be extended, and the peak value will be greater. On the other hand, the intervention of technical factors, REEs end-use industry development, and political factors will cause the change of intrinsic growth ' $a$ ', and subsequently increase peak production. At the same time, the life cycle of the resource's exploitation will be shortened, which coincides with the scenario simulation results.

In addition, the changes of the impact factors will influence the trends and the peak of the production, including technical factors, the development of REEs end-use industries, intervention factors, political factors, and other factors. For simplicity, we simulated the changes of the above impact factors together through the intrinsic growth rate ' $a$ ', instead of separately considering the effect on China's REEs production of individual change in the impact factors, since the historical data and trends reflect the coupled impact of the above factors. However, because of these factors' uncertainty, the possibility cannot be excluded that the future production and the peak time will have to be different from the results predicted in this paper. Ideally, these differences will involve the forecast's trend-line fluctuations. 
By comparison, we found that there is a big difference between our results and Wang et al. [17]. The difference in results may be for three reasons. The first is the different prediction objects. Wang et al. [17] made predictions on three kinds of main rare earth elements, including mixed rare earths, ionic rare earths, and bastnaesite, while this paper made predictions on the total amount of rare earth elements. The second reason is the different sources of previous production data. The data on rare earth elements production from 1994 to 2012 in this paper was from the USGS (U.S. Geological Survey) Mineral Commodity Summaries, while the data in Wang et al. [17] was from The National Development and Reform Commission, Industry Coordination Department. The disparity of previous data on production from the different sources resulted from a different statistic caliber. The third reason is the different variables between the generalized Weng model and the systematic dynamics model based on the Hubbert model. The variables involved in the generalized Weng model are the prediction model constants $a, b$, and $c$, and the exploitation time $t$, among which the former three can be gotten from actual production by fitting; while the systematic dynamics model based on the Hubbert model in this paper takes technological advances, the development of REEs end-use industries, policy interventions, politics, and other factors into comprehensive consideration (in addition to recoverable reserves), and these factors are represented by the intrinsic growth rate ' $a$ '. Future REEs production is thus estimated by the simulation of different ' $a$ '. Compared with the generalized Weng model, the systematic dynamics model based on the Hubbert model used in this study takes more factors into consideration, which leads to a difference in predicted results between the two models.

\section{Conclusions and Recommendations}

\subsection{Conclusions}

REEs are indispensable elements in modern industry, because of their unique physical and chemical properties and their wide applications. Based on the important position in the world of China's REEs production and the development of REEs-related industries, China's REEs supply and peak prediction have increasingly been the target of interest of researchers worldwide. To achieve more accurate results, this paper applies the Hubbert model to simulate China's REEs production peak and trends. The following conclusions have been drawn based on the forecasting results.

(1) The Hubbert model is applicable in the field of REEs supply issues.

As a peak predictive model, the Hubbert model is usually used in forecasting the peak and trends of nonrenewable resource production. Similar to other exhaustible resource, the REEs production curve is a bell-shaped curve that gradually increase to maximum output and then keep a short peak, finally gradually decline. When the output reached the maximum point, the production will not increase any more. The Hubbert model is adopted in this paper to study production peak and trends of China's REEs. By comparing the real and forecasted production of China's REEs from 2007 to 2011, we find that the average difference rate is small and in main result it is less than $10 \%$, which means that the Hubbert model is rational and applicable for China's REEs production forecasting.

(2) China's REEs production peak will appear by the middle of the 21st century.

According to the simulation, considering the varying range of ' $N_{R}$ ' and the parameter ' $a$ ', the peak of REEs production in China will occur between 2034 and 2042, with peak productions of approximately 232,400 to 384,700 tons. Chinese REEs output will grow approximately $2.5 \%$ annually before peaking, and will decrease afterwards.

(3) A positive correlation exists between the production peak and the parameters of ' $N_{R}$ ' and ' $a$ '.

Theoretically, advances in technology will increase the value of ' $N_{R}$ '. Similarly, changes in technology, policy, and the development of REEs end-use industries will bring about the change of parameter ' $a$ ', and thus affect the trends and peaks of REEs production. The results of the 
scenario analysis indicate that the life cycle of China's REEs production will be extended, and the peak value will be greater, when the ' $N_{R}$ ' value is increased by the influence of technological advances. Similarly, if the parameter ' $a$ ' is increased through the influence of the above-mentioned factors, the REEs production peak will increase, but the life cycle in China will be shortened.

\subsection{Policy Recommendation}

Based on the conclusions above, some policy suggestions are proposed, as follows.

\subsubsection{Policy Recommendations for China}

Increase exploration efforts. China should actively develop geological exploration technology, and intensify geological prospecting to find new REEs mines, since China is a country rich in REEs. The world will face a serious shortage of REEs supply without China's active participation, and China will then lose great opportunities for profit in the world market if the peaking time comes as predicted in this paper, since the REEs end-industry will continue to develop, and great demand can be expected at that time.

Increase the recovery ratio. In China, the technologies for mining in REEs production are far from advanced. Some small- and medium-sized companies only skim the upper rich layer of REEs minerals with rough equipment or tools. The mining recovery rate is low. At present, the average recovery rate of REEs resources from the state-owned mines is $60 \%$, whereas that from the private mines is less than $40 \%$, and that from most of the illegal mines is only 5\% [58]. The life cycle of China's REEs resources will be extended, and the arrival of China's REEs production peak will be put off, if the recovery ratio of REEs can be increased and the intrinsic growth rate ' $a$ ' can be reduced.

\subsubsection{Policy Recommendations for Other Countries}

Countries with rich REEs resources should restart their REEs mines to gradually reduce their dependence on China's REEs, and attempt to explore substitutes for REEs and alternative technologies. According to the forecasts, China's REEs resources will peak by the middle of the 21st century. With the development of REEs-related industries, the demand for REEs will continue to increase. Given the pattern of supply of REEs in the world (China accounting for $97 \%$ of the world's supply of REEs), a worldwide REEs supply and demand gap will appear after the peak. Thus, REEs resource-rich countries should consider restarting their REEs mines to relieve the world's REEs supply pressure.

Countries without resource endowments should make efforts in the development of REEs recycling technologies, and in seeking substitutes for REEs resources in addition to alternative technologies.

5.2.3. Global Efforts at Forming a Sustainable Exploitation and Utilization Mechanism for Rare Earth Element Resources

International communities should establish a sustainable development organization for world rare earth elements resources-just like Organization of the Petroleum Exporting Countries in the field of petroleum - in order to form a sustainable exploitation and utilization mechanism for the resources, from the perspective of a worldwide effort to protect an important resource, and ensure its sustainable development in terms of an ecological economy. International communities should aim at realizing the efficient and sustainable exploitation, utilization, and optimized allocation of rare earth elements, including building a rare earth elements price-forming mechanism, a rare earth elements technological innovation mechanism, an ecological environment compensation mechanism, and a unified supervision and management mechanism, by the macro overall planning and scientific management of the world's rare earth elements resources. 
Acknowledgments: Authors would like to thank the reviewers of this journal for helpful comments and suggestions. This research is supported by National Natural Science Foundation of China (41601596), China Postdoctoral Science Foundation (2017M610043) and the project of Key Laboratory of Carrying Capacity Assessment for Resource and Environment of Ministry of Land and Resource (CCA2016.09). Any errors and all views expressed remain our own.

Author Contributions: X.W. and M.Y. conceived and designed the experiments; J.L. performed the experiments; H.Z. and X.W. analyzed the data; M.Y. contributed reagents/materials/analysis tools; X.W. and M.Z. wrote the paper; X.W. and K.Z. responded the comments.

Conflicts of Interest: The authors declare no conflict of interest.

\section{Appendix}

(1) $\mathrm{a}=0.057$

(2) actual production $=$ production

Units: tons

(3) annual proved reserves addition $=$ hubbert prd + delta resv

Units: tons

(4) cumulative prd = INTEG (hubbert prd, $1.71683 \times 10^{6}$ )

Units: tons

(5) cumulative proved reserves = INTEG (annual proved reserves addition, $8.9 \times 10^{7}$ )

Units: tons

(6) $\quad$ deltaresv $=$ DELAY1 $($ proved reserves, 1$)$

Units: tons

(7) FINAL TIME $=2100$

Units: year

The final time for the simulation.

(8) hubbertprd $=$ IF THEN ELSE (Time $\leq$ 2005, actual production, (1-cumulative prd/ultimate reserves) $\times$ cumulative prd $\times$ a)

Units: tons

(9) INITIAL TIME $=1988$

Units: Year

The initial time for the simulation.

(10) production $=$ WITH LOOKUP (

Time,

((1988,29640),(1989,25220),(1990,16480),(1991,16150),(1992,21340),(1993,22100),(1994,30600),

$(1995,48000),(1996,55000),(1997,53300),(1998,65000),(1999,70000),(2000,73000),(2001,73000)$,

$(2002,88000),(2003,92000),(2004,95000),(2005,119000),(2006,120000),(2007,120000),(2008,120000)$, $\left.\left.(2009,129000),(2010,130000),(2011,105000),\left(2100,9 \times 10^{12}\right)\right)\right)$

Units: tons

(11) proved reserves $=$ hubbertprd $\times \mathrm{R}$ vs $\mathrm{P}$

Units: tons

(12) R vs. P = WITH LOOKUP (

Time,

$((1988,627),(1989,736),(1990,1125),(1991,1147),(1992,867),(1993,836),(1994,603),(1995,384),(1996,334)$, $(1997,344),(1998,281),(1999,260),(2000,248),(2001,247),(2002,204),(2003,195),(2004,187),(2005,149)$, $(2006,147),(2007,146),(2008,145),(2009,134),(2010,132),(2011,162),(2020,1000),(2050,10000)))$

(13) replacement rate $=$ annual proved reserves addition/hubbert prd

(14) ultimate reserves $=1.859 \times 10^{7}$

Units: tons 


\section{References}

1. Mclellan, B.C.; Corder, G.D.; Ali, S.H. Sustainability of Rare Earths-An Overview of the State of Knowledge. Minerals 2013, 3, 304-317. [CrossRef]

2. Wübbeke, J. Rare earth elements in China: Policies and narratives of reinventing an industry. Resour. Policy 2013, 38, 384-394. [CrossRef]

3. He, C.; Lei, Y. Potential Impact of U.S. Re-Emerging Rare Earths Industry on Future Global Supply and Demand Trend. Int. Bus. Res. 2013, 6. [CrossRef]

4. Wang, X.; Ge, J.; Li, J.; Han, A. Market impacts of environmental regulations on the production of rare earths: A computable general equilibrium analysis for China. J. Clean. Prod. 2017, 154, 614-620. [CrossRef]

5. Kingsnorth, D.J. Rare earths: Facing new challenges in the new decade. Proceedings of SME Annual Meeting, Phoenix, AI, USA, 28 February-3 March 2010.

6. Kingsnorth, D.J. Rare Earths: Facing New Challenges in the New Decade. In Proceedings of the 2010 SME Annual Meeting, Phoenix, AZ, USA, 28 February-3 March 2010.

7. Chen, Z.H. Global rare earth resources and scenarios of future rare earth industry. J. Rare Earths 2011, 29, 1-6. [CrossRef]

8. Laherrere, J.H. Learn strengths, weaknesses to understand Hubbert curve. Oil Gas J. 2000, 98, 63.

9. Laherrere, J. Comments on the Book: Hubbert's Peak: The Impending World Oil Shortage. Available online: http://www.oilcrisis.com/laherrere/Deffeyes_comments.pdf (accessed on 11 August 2016).

10. Laherrere, J. Oil and Natural Gas Resource Assessment: Production Growth Cycle Models. Encycl. Energy 2004, 4, 617-631.

11. Bartlett, A.A. An Analysis of U.S. and World Oil Production Patterns Using Hubbert-Style Curves. Math. Geol. 2000, 32, 1-17. [CrossRef]

12. Zheng, M.; Chen, Y. Supply and demand of global rare earth resources and China's rare earth industry policy. Nonferrous Met. Sci. Eng. 2012, 4, 14.

13. Hurst, C. China's Rare Earth Elements Industry: What Can the West Learn? Institute for the Analysis of Global Security: Washington, DC, USA, 2010.

14. Castor, S.B.; Hedrick, J.B. Rare Earth Elements. Available online: http://www.fieldexexploration.com/ images/property/1_RareEarths_FLX_02.pdf (accessed on 11 November 2016).

15. Ting, M.H.; Seaman, J. Rare Earths: Future Elements of Conflict in Asia? Asian Stud. Rev. 2013, 37, $234-252$. [CrossRef]

16. Ting, M.H. China and the Supply Chain of Rare Metals: Table of [dis]contents. East Asia Forum. Available online: http:/ / www.eastasiaforum.org/2010/11/11/china-and-the-supply-chain-of-rare-metals-table-ofdiscontents/ (accessed on 14 May 2011).

17. Wang, X.; Lei, Y.; Ge, J.; Wu, S. Production forecast of China's rare earths based on the Generalized Weng model and policy recommendations. Resour. Policy 2015, 43, 11-18. [CrossRef]

18. Brecha, R.J. Ten Reasons to Take Peak Oil Seriously. Sustainability 2013, 5, 664-694. [CrossRef]

19. Schindler, J.; Zittel, W. Crude Oil-The Supply Outlook; Energy Watch Group: Berlin, Germany, 2008.

20. Höök, M.; Aleklett, K. Historical trends in American coal production and a possible future outlook. Int. J. Coal Geol. 2009, 78, 201-216. [CrossRef]

21. Höök, M.; Zittel, W.; Schindler, J.; Aleklett, K. Global coal production outlooks based on a logistic model. Fuel 2010, 89, 3546-3558. [CrossRef]

22. Lin, B.Q.; Liu, J.H. Estimating coal production peak and trends of coal imports in China. Energy Policy 2010, 38, 512-519. [CrossRef]

23. Li, M. Peak Energy and the Limits to China's Economic Growth: Prospect of Energy Supply and Economic Growth from Now to 2050; Working Papers Series; PERI: Amherst, MA, USA, 2008.

24. Li, M. Peak Energy, Climate Change, and Limits to China's Economic Growth. Chin. Econ. 2012, 45, 74-92. [CrossRef]

25. Patzek, T.W.; Croft, G.D. A global coal production forecast with multi-Hubbert cycle analysis. Energy 2010, 35, 3109-3122. [CrossRef]

26. Maggio, G.; Cacciola, G. A variant of the Hubbert curve for world oil production forecasts. Energy Policy 2009, 37, 4761-4770. [CrossRef] 
27. Mohr, S.; Höök, M.; Mudd, G.; Evans, G. Projection of long-term paths for Australian coal production-Comparisons of four models. Int. J. Coal Geol. 2011, 86, 329-341. [CrossRef]

28. Feng, L.; Li, J.; Pang, X. China's oil reserve forecast and analysis based on peak oil models. Energy Policy 2008, 36, 4149-4153. [CrossRef]

29. Hu, J.G.; Chen, Y.Q.; Zhang, Z.S. A new model for Forecast oil and gas production and recoverable reserves. J. Oil 1995, 16, 79-86.

30. Chen, Y.Q.; Hu, J.G. Weng's model for review and the new derived. China's Offshore Oil Gas (Geol.) 1996, 10, 317-324.

31. Lv, M.; Shi, H.; Zheng, N.; Zou, G. Coalbed Methane Production Forecast Method Based on Generalized Weng's Model. China Coalbed Methane 2012, 6, 35-38.

32. Tang, X.; Feng, L.; Zhao, L. Prediction and analysis of world oil supply Pattern based on generalized Weng's model. Resour. Sci. 2009, 31, 238-242.

33. Qiang, S.; Bing, D.; Limei, M. Application of generalized Weng's model and Rayleigh model in recoverable reserves. J. Oil 1995, 16, 79-86.

34. Tao, Z.; Li, M. What is the limit of Chinese coal supplies-A STELLA model of Hubbert Peak. Energy Policy 2007, 35, 3145-3154. [CrossRef]

35. Li, J.C.; Dong, X.C.; Shangguan, J.X.; Hook, M. Forecasting the growth of China's natural gas consumption. Energy 2011, 36, 1380-1385. [CrossRef]

36. Frausto-Solis, J.; Chi-Chim, M.; Sheremetov, L. Forecasting Oil Production Time Series with a Population-Based Simulated Annealing Method. Arab. J. Sci. Eng. 2015, 40, 1081-1096. [CrossRef]

37. Hubbert, M.K. Nuclear Energy and the Fossil Fuel. Drilling and Production Practice; American Petroleum Institute: Washington, DC, USA, 1956.

38. Hubbert, M.K. Techniques of Erediction with Application to the Petroleum Industry; Shell Development Company, Exploration and Production Research Division: Houston, TX, USA, 1959.

39. Campbell, C.J. The Twenty First Century the World's Endowment of Conventional Oil and Its Depletion. Available online: http:/ / www.hubbertpeak.com/campbell/camfull.htm (accessed on 12 September 2016).

40. Campbell, C.J. Forecasting Global Oil Supply 2000-2050. Available online: http://www.hubbertpeak.com/ campbell/Campbell_02-3.pdf (accessed on 6 January 2017).

41. Wattenbarger, R.A. Oil production trends in the CIS. World Oil 1994, 215, 91-96.

42. Ivanhoe, L.F. Updated Hubbert curves analyze world oil supply. World Oil 1996, 217, 91-94.

43. Al-Jarri, A.S.; Startzman, R.A. Worldwide Petroleum-Liquid Supply and Demand. J. Petroleum Technol. 1997, 49, 1329-1338. [CrossRef]

44. Gallagher, B. Peak oil analyzed with a logistic function and idealized Hubbert curve. Energy Policy 2011, 39, 790-802. [CrossRef]

45. Nashawi, I.S.; Malallah, A.; Al-Bisharah, M. Forecasting World Crude Oil Production Using Multicyclic Hubbert Model. Energy Fuels 2010, 24, 1788-1800. [CrossRef]

46. Mohr, S.H.; Evans, G.M. Forecasting coal production until 2100. Fuel 2009, 88, 2059-2067. [CrossRef]

47. Wang, J.; Feng, L.; Tverberg, G.E. An analysis of China's coal supply and its impact on China's future economic growth. Energy Policy 2013, 57, 542-551. [CrossRef]

48. Imam, A.; Startzman, R.A.; Barrufet, M.A. Multicyclic Hubbert model shows global convential gas output peaking in 2019. Oil Gas J. 2004, 102, 20.

49. Al-Fattah, S.M.; Startzman, R.A. Forecasting World Natural Gas Supply. J. Petroleum Technol. 2000, 52, 62-72. [CrossRef]

50. Study CERA. Oil production to track "undulating plateau". Oil Gas J. 2006, 104, 32-33.

51. Cheney, E.S.; Hawkes, M.W. The future of hydrocarbons: Hubbert's peak or a plateau. GSA Today 2007, 17, 69-70. [CrossRef]

52. Lynch, M.C. The New Pessimism about Petroleum Resources: Debunking the Hubbert Model (and Hubbert Modelers). Miner. Energy Raw Mater. Rep. 2003, 18, 21-32. [CrossRef]

53. Jackson, P.M. Peak Oil Theory Could Distort Energy Policy and Debate. J. Petroleum Technol. 2007, 59, $24-28$. [CrossRef]

54. Bendor, T.K. The System Dynamics of U.S. Automobile Fuel Economy. Sustainability 2012, 4, 1013-1042. [CrossRef] 
55. The National Development and Reform Commission, Industry Coordination Department. China's Rare Earths. Rare Earths Information 1989-1994; The National Development and Reform Commission, Industry Coordination Department: Beijing, China. (In Chinese)

56. US Geological Survey. Minerals Information, Rare Earths Statistics and Information 1995-2013. Available online: http://minerals.usgs.gov/minerals/pubs/commodity/rare_earths/ (accessed on 19 January 2017).

57. The National Development and Reform Commission, Industry Coordination Department. China'S Rare Earths, Rare Earths Information, 1998-2011; The National Development and Reform Commission, Industry Coordination Department: Beijing, China. (In Chinese)

58. Zhang, S. Problems and Countermeasures of Rare Earth Industry in China. Can. Soc. Sci. 2013, 9, 9-14.

(C) 2017 by the authors. Licensee MDPI, Basel, Switzerland. This article is an open access article distributed under the terms and conditions of the Creative Commons Attribution (CC BY) license (http://creativecommons.org/licenses/by/4.0/). 